\title{
Educational Tourism as an Engine in Learning Foreign Languages
}

\author{
Oksana Poletaeva ${ }^{1},{ }^{*}$ Narkiza Moroz ${ }^{2}$, Oksana Lazareva ${ }^{2}$ \\ ${ }^{1}$ National Research University of Electronic Technology, Moscow, Russia \\ ${ }^{2}$ University of Tyumen, Tyumen, Russia \\ *Email: poletaeffs@mail.ru
}

\begin{abstract}
The article explores educational tourism and identifies its role in learning foreign languages. The authors look into the language policy of universities through the academic mobility of students and teachers. Based on the research subject, the authors analyse relevant literature and use the empiric observation method and questionnaire of educational tourists. They also consider foreign language studying options at their native universities and compare them with the ways of studying at other universities in the context of educational tourism. The research shows the most popular forms of educational tourism for students studying foreign languages. It allows connecting travel experience and students' motivation to study. The paper will be helpful for researchers who try to optimise the educational process of learning languages by applying educational tourism and for people interested in improving their language skills and overcoming the language barrier.
\end{abstract}

Keywords: Educational tourism, Academic tourism, Digital natives, Higher education

\section{INTRODUCTION}

Studying a foreign language at a university is a practical form of language policy. At university, students should acquire life and work skills necessary for their professional success in the future. Language skills are efficient in various spheres of international activities, allowing them to participate globally in business, sport, education, science, culture, etc. "English has become a global language for communication, and it is important for social and business interaction. Thus, through education, learners are expected to develop the necessary competence to communicate efficiently" [1]. The main aim of the conducted research was to identify the role of educational tourism in learning foreign languages. We investigated the language policy of universities through the academic mobility of students and teachers; we analysed educational tourism from the tourists' point of view. Academic mobility is one of the main ideas of the Bologna Process: each university has its strategy. This strategy aims to develop the competitiveness of future specialists in their professional sphere [2]. Academic mobility is intended to develop the internationalisation of higher education and cultural integration of the youth of different countries [3].

"There are many reasons for academic mobility, including the processes of globalisation that led to the opening of borders, which in the past were problematic enough to cross, the low level of education in the countries of students' origin, increased ambitions and financial opportunities of the middle class, the purposeful policy of some states to raise the level of human resources to help ensure economic growth and improve national educational standards, international rankings, etc." [4, p. 507].

\section{LITERATURE REVIEW}

During the research, the authors explored publications devoted to the problem of teaching students and using technologies to make studying more effective and challenging. Higher education will inevitably be on the rising trend, as it is the most demanded sector, with the blooming of local and private universities worldwide [5]. 
Modern students belong to the generation of the "Digital Natives", a "specific population of students born after 1980, who have access to digital technology, and possess digital literacy skills" [6, p. 23]. So, universities should consider this fact while developing their plans of action. "Tertiary education does not meet society's expectations, the modern requirements of the labour market, current and future demands of the economy" unless students perceive the world through a cultural lens [7, p. 711].

Non-formal education also plays a vital role in obtaining new knowledge and skills for future work, expanding their horizons, implementing their projects. According to the results of some researches, "the motivation of the majority of young people is based on the desire to gain professional competencies, success in future work and competitiveness" [8, p.315].

Education is also connected with educational migration, as young people want to get "access to the latest technologies, world culture, quality education, and international markets" [9].

Even though academic mobility plays a significant role in developing students and teachers' professional skills, it is not very common for Russian universities. During our study, we analysed the academic mobility of a regional university (Fig.1).

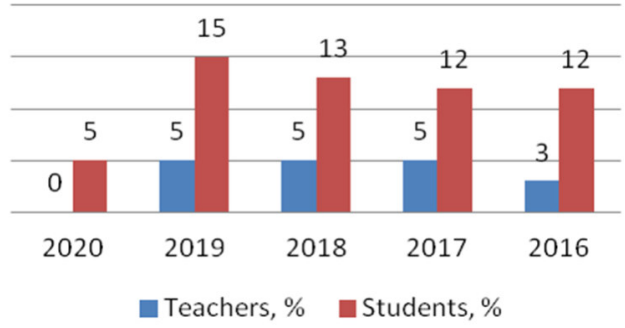

Figure 1 Academic mobility of teachers and students (2016-2020).

We found out that since 2016 students' mobility has risen by $3 \%$, whereas teachers' academic mobility was stable from 2016 to 2019, and it declined in 2020. The world pandemic of coronavirus must explain this situation.

We also investigated materials on academic tourism; "from the economic perspective, academic tourism has a relatively greater economic impact than conventional tourism (it is a relatively more efficient type of tourism)" [10, p.93].

Academic tourism includes two types: scientific and educational tourism [11]. In this article, we are speaking about educational one. Educational tourism is increasingly recognised as an essential tool to "support sustainability action and change. With more than one billion people travelling each year internationally, we must develop effective ways to educate and encourage these travellers..." [12].

"Educational tourism has a bi-directional causal relationship with economic growth in the short-run" [13]. It is characterised as "cognitive tours, the aim of which is to fulfil tasks defined by the curricula of educational institutions" [14]. No doubt, there has been a focus on educational tourism (Carr, 2002; Cooper and Shepherd, 1997; Donaldson and Gatsinzi, 2006; Gibson, 1998; Ritchie and Hudson, 2009; Zhukovskaya and Generalova 2017) [15-20], but there are only a few studies, looking basically at the subjective experience of educational tourists like self-improvement, relaxation, learning as fun, a mixture of concepts.

Thus, educational tourism has not been a thoroughly studied area in the academic literature, despite the emphasis on tourism as an inherently educational activity [21] and the highlighted need for research exploring learning experiences in tourism [22, 23-24]. We can say that both education and educational tourism industries have grown in recent years, which led to the growing recognition of these industries from economic and social perspectives $[25$, p. 64$]$. The main aim of educational tourism is to educate students to identify and understand problems in sustainable tourism development [26].

Language tourism develops communicative competence in acquiring foreign languages, which is very important in any sphere of professional life [27]. Many scientists consider such personality traits as curiosity, altruism, and being open-minded to new experiences to be predictors of global learning, which is fostered by educational tourism [28]. Unfortunately, the legislation system of Russia lacks the concept of "educational tourism", although the terms "Tourism" [29] and "Education" [30] are defined.

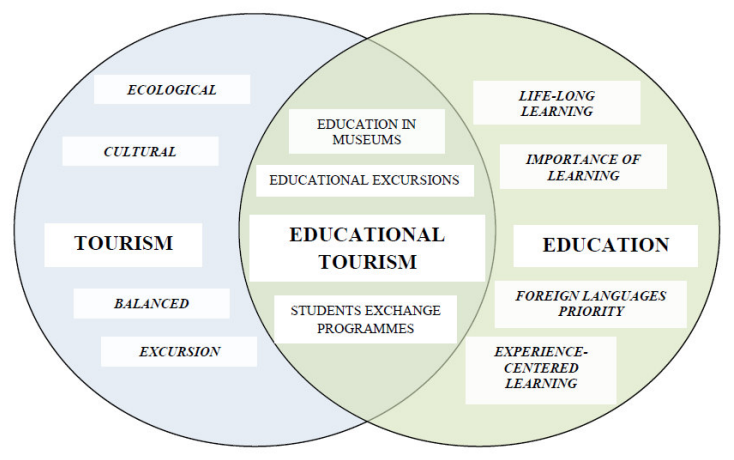

Figure 2 Structure of the "Educational Tourism" concept.

According to V. Solomin, capacity, sustainability, reliability and availability are distinguished as four dimensions of educational tourism resources [14]. The interpenetrating mixture made the concept of Educational 
Tourism of two notions: Tourism and Education (Fig.2). Tourism is a multi-complex area involving such aspects as ecological, cultural, excursion trips, and balanced tourism. Balanced tourism is quite a new aspect resulting from the significant impact of tourist activities on the local environment.

Modern trends of education concentrate on constant non-stop learning with a high degree of awareness of learning foreign languages importance in the global context of the current world. Therefore, any type of education should foresee the practical applications of the skills acquired while studying, so the need to implement them reflects the growing demand for educational tourism services.

Educational tourism combines tourism and education and expands into further adherent areas. Thus, the popularity and demand of all types of students' exchange programs will undoubtedly increase. Designing field trips or professional tours, the organisers should consider students' basic needs: physiological, psychophysical, emotional expressions, social, needs for a change, selfactualisation needs, intellectual development, the exploration and development of creative potential [30].

\section{MATERIALS AND METHODS}

The subject of the research is educational tourism of university students to improve language learning skills. Along with the scientific method of literature review, the authors used the empiric observation method and questionnaire of educational tourists. The experience of teaching foreign languages at different universities, comparing it with our own experience, was also analysed.

The study shows that learning a foreign language should be based on interdisciplinary integration with the help of innovative forms and methods. Besides, we are sure that the essential form of learning a foreign language takes place away from the classroom environment.
There are many things students can do to accelerate their progress; for example, speaking English conversationally is a great way to get their confidence up, and they will pick up new words and phrases almost without even realising it.

What is more, they will learn the colloquial language spoken by native Brits every day - the constantly evolving slang that language books do not tend to teach them. While "real-life" English-speaking friends are great for helping students develop their conversational English skills, corresponding with a pen friend by letter or email will help develop their written English; they will also develop their reading skills on receiving their response. If they have an opportunity to go abroad and master a language there, they will have more chances to achieve the main goal of their studies: to communicate their ideas to other people clearly and fast. We insist that educational tourism is one of the most effective training tools for specialists at university.

To achieve the aim of the research, we turned to the students who participated in educational tourism programs (Table 1). We wanted to know what they had liked about the program and what they would change to increase the outcome and effectiveness of studies abroad.

We were interested in whether they had really gained new language skills and knowledge and learned about the culture and traditions of a new country.

Besides, we asked questions about the problems and challenges the students had faced during their trip, e.g., if they had experienced a cultural shock and language barrier, what they had thought about communication in the host family they stayed at.

All the participants of the language program believe that they had improved their knowledge of English and had learnt a lot about the country and its culture. Practically everybody would like to do these courses again. In the pandemic context, we also wanted to know whether the students are ready to take online language

Table 1 Results of educational tourism (\%)

\begin{tabular}{|l|c|c|c|}
\hline \multicolumn{1}{|c|}{ Questions } & Yes (\%) & Not sure (\%) \\
\hline Did you improve your English? & 92 & 7 & 1 \\
\hline $\begin{array}{l}\text { Did you gain knowledge about the } \\
\text { country? }\end{array}$ & 87 & 20 & 2 \\
\hline $\begin{array}{l}\text { Would you like to take an English course } \\
\text { in future? }\end{array}$ & 76 & 50 & 38 \\
\hline $\begin{array}{l}\text { Would you like to take online language } \\
\text { courses? }\end{array}$ & 12 & & 4 \\
\hline
\end{tabular}


courses if the borders are closed, and they cannot physically go to another country.

We were surprised at the survey result as only $12 \%$ of the respondents agreed to do online courses. It means that a lively atmosphere at the lessons and feeling "here now" with other people interested in communication in the language you are learning is very important. It is immersion in the language environment that makes learning exciting and compelling.

At our university, we offer participation in such programs as an opportunity to improve the qualifications of future specialists in conditions as close as possible to their professional sphere, using the basic knowledge gained in practical classes with a teacher. In foreign language centres (Hilderstone College, St Giles International, London House School of English, etc.), our students face the challenge of working with native speakers in the real situation, thus improving their language level by communicating with the international students and the local inhabitants. It is important to note that the learners obtain opportunities to acquire particular practical competencies, choosing their learning program.

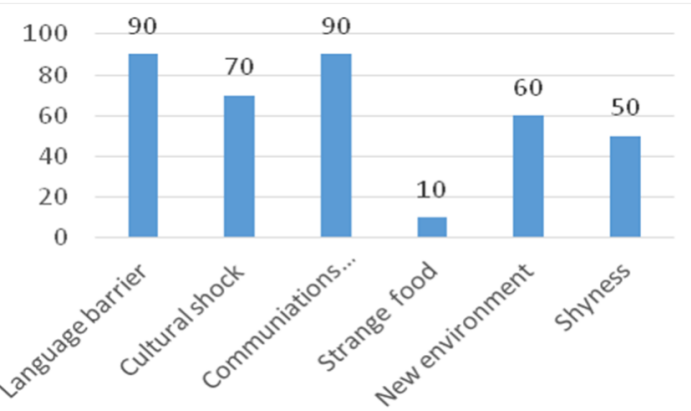

Figure 3 Difficulties that students faced (\%).

When a person comes to another country, he should overcome the language barrier, which is not easy; it is difficult for Russian students to speak fluently without thinking about accuracy. This causes communication failures that are encountered by $90 \%$ of the respondents. $70 \%$ of travellers had cultural shock as they saw a different culture in a new environment. Shyness was also a problem for many students.

\section{DISCUSSION}

Besides, it is interesting to note that despite all the benefits of experiential learning from field trips, not all students choose to attend the organised field trips for various reasons. One of the reasons is the country's past. Russia was a closed country for a long time. Nowadays, some adults and their children think that they will not need a foreign language in the future. They are sure that their professional life will not relate to international companies or something like this. They do not understand that knowledge is power. In general, students are reluctant to practice a foreign language because of the language barrier. They are afraid of making mistakes. However, it is a process of acquiring knowledge.

Teaching foreign languages at university aims to master the necessary and sufficient level of professional, communicative competence to solve general communicative problems in professional, translation and scientific-cognitive activities. The university program should be intended to broaden horizons, increase students' common and professional culture, develop information culture, and study on their own.

Based on the results of this research, future studies on educational tourism for digital native students will explore the use of such a format of education to support students' motivation and interest in learning foreign languages. These include, but are not limited to, students' preferences and choices and educational programs in foreign language teaching.

\section{CONCLUSION}

Learning a foreign language through educational tourism is a primary way of improving these skills. However, it is a commonplace that educational institutions cannot provide all students with such educational tourism opportunities. Therefore, it is appropriate to introduce the selection procedure mode for participants on competitive grounds. Similar to grant programs for internships in foreign universities, such as ERASMUS, universities of Russia need to introduce internal contest challenges giving students a chance to travel for educational purposes. Such competitions can boost their interests in the education process. Incentive tourism has become common abroad and ubiquitous among Russian employers in successful companies. Nevertheless, this term has not been applied to education yet. Introducing these tours on a competitive basis, paying a specific part of the costs in case of successful competition completion will increase students' interest and motivation.

As in the case of framework agreements between various universities aiming at student exchange, universities of Russia managing educational tours can make contracts with the host, catering and hospitality establishments. They may obtain adequate service at a reduced cost or, by mutual agreement of the parties, a part of services can be provided at the expense of the receiving party.

Students' motivation and financial incentives to study abroad should carry access to new learning experiences, higher quality education, fewer expenses, gaining selfconfidence through travelling, and becoming more adaptable in a new environment.

To develop and maintain educational tourism effectively, specific criteria are to be considered. It is necessary to decide if we deal with an adult (university 
teachers and professors) or non-adult (teenagers and high school students) learning tours.

It is essential to choose appropriate language schools abroad with entertaining activities and educational resources.

Moreover, educational tourism can be personalised and organised formally or informally, including pedagogical, psychological, interdisciplinary and intercultural features.

\section{CONTRIBUTION OF THE AUTHORS}

Moroz N.A. - development of the concept, methodology and research tools, literature analysis, conducting the research, revision and proofreading the text.

Lazareva O.P. - development of the concept, methodology and research tools, literature analysis, data collection, conducting the research.

Poletaeva O.B. - literature selection and analysis, data collection, conducting the research.

\section{REFERENCES}

[1] L. Ledesma, J. Izquierdo, Digital natives and technology for L2 learning outside of the classroom // Apertura 12(1) (2020) 1-19.

[2] V. Galichin, E. Karpukhina, V. Matveev, A. Sugakova, Academic mobility in the conditions of internationalisation of education, Moscow: University book, 2009.

[3] I. Mikova, Academic mobility of students in Russian higher educational institutions // Bulletin of Ryazan state university 26 (2010) 45-53.

[4] A. Serikkalieva, G. Nadirova, N. Saparbaeva, Educational migration from Kazakhstan to China: reality and perspectives // Integration of Education 4(23) (2019) 504-517. DOI: https://doi.org/10.15507/1991$\underline{9468.097 .023 .201904 .504-517}$

[5] J. Lam, B. Kai, C. Chen, Edutourism: the study of tourism behaviour of international students in Malaysia // Proceeding of the International Conference on Social Science, Economics and Art. 2011, pp. 207-212.

[6] T. Thurston, Design Case: Implementing Gamification with ARCS to Engage Digital Natives // Journal on Empowering Teaching Excellence 2(1) (2018) 23-50.

[7] I. Aleshkovski, A. Gasparishvili, O. Krukhmaleva, A. Onosov, Students' Perceptions of Quality in Higher Education and Career Choices: A Case
Study of the Russian Industrial Region // European Journal of Contemporary Education 9(4) (2020) 710-725. DOI: http://ejournal1.com/journals_n/1608756217.pdf

[8] G. Efimova, E. Zuban, M. Kicherova, E. Muslimova, Paradoxes of Non-formal Education of Students // Integration of Education 2(23) (2019) 303-321. DOI: https://doi.org/10.15507/19919468.095.023.201902.303-321

[9] V. Strielkovski, S. Kiseleva, A. Sineva, Tendencies of International Migration (on the example of Finland) // Integration of Education 1(24) (2020) 32-49. DOI: $\quad$ https://doi.org/10.15507/19919468.098.024.202001.032-049

[10] X. Rodríguez, F. Martínez-Roget, E. Pawlowska, Academic tourism: A more Sustainable Tourism // Regional and Sectoral Economic Studies 13 (2013) 89-98

[11] A. Matveevskaya, Academic Tourism as an Instrument of Formation of International Educational Space // Works of BusinessCommunication Institute 1 (2017) 115-127.

[12] L. Ruhanen, L. Bowles, Student Perspectives of Responsible Tourism Behaviour: The Role of Tourism Education // Journal of Hospitality \& Tourism Education 32(4) (2020) 255-265. DOI: https://doi.org/10.1080/10963758.2019.1688160

[13] M. Hylmee, Chor Foon Tang. Educational Tourism and its Implications on Economic Growth in Malaysia // Asia Pacific Journal of Tourism Research 22(11) (2017) 1110-1123, DOI: https://doi.org/10.1080/10941665.2017.1373684

[14] V. Solomin, V. Pogodin, Modern Situation and Perspectives of Development of Educational Tourism in Russia // Bulletin of Russian Pedagogical University of Gergen 8(30) (2007) 96112.

[15] C. Cooper, J. Latham, School Trips. An Uncertain Future? // Leisure Management 9(4) (1989) 73-75.

[16] C. Cooper, R. Shepherd, The Relationship Between Tourism Education and the Tourism Industry: Implications for Tourism Education. // Tourism Recreation Research 22(1) (1997) 34-47.

[17] R. Donaldson, J. Gatsinzi, Foreign Students as Tourists: Educational Tourism, a Market Segment with Potential. Africa Insight, No. 35, 2006. DOI: https://doi.org/10.4314/ai.v35i3.22441

[18] H. Gibson, The Educational Tourist // The Journal of Physical Education, Recreation \& Dance 69(4) (1998) 32-34. 
[19] J. Ritchie, S. Hudson, Understanding and Meeting the Challenges of Consumer/ Tourism Experience Research. International Journal of Tourism Research 11 (2009) 111-126.

[20] I. Zhukovskaya, G. Generalova, Educational Tourism: Essence, Goals, Development Prospects in Russia // Global scientific potential 11(80) (2017) 107-111.

[21] C. Smith, P. Jenner, Market Segments: Educational Tourism // Travel and Tourism Analyst 3 (1997) 6075.

[22] E. Lunin, Improving the Management of Educational Tourism in the Russian Federation: autoref. dis. cand. econ. Sciences, St. Petersburg, 2009, $156 \mathrm{p}$.

[23] N. Carr, The Tourism - Leisure Behavioural Continuum // Annals of Tourism Research 29 (2003) 972-86.

[24] N. Carr, University and College Students' Tourism // Managing Educational Tourism. UK: Channel View Publications, 2003, pp. 181-225.

[25] J. Lam, A. Ariffin, A. Ahmad, Edutourism: Exploring the Push-Pull Factors in Selecting a University // International Journal of Business and Society 12(1) (2011) 63-78.

[26] F. Mohd-Taib, M. Saariwijaya, An Assessment of the Edu-Tourism // AJTLHE 12(2) (2020) 46-57.

[27] Ch. McGladdery, B. Lubbe, International Educational Tourism: Does it Foster Global Learning? A survey of South African High School Learners // Tourism Management 62 (2017) 292301.

[28] Federal Law of 24.11.1996, No. 132-FZ "Grounds of Tourism Activities". Retrieved from: I www.consultant.ru/ document/cons_doc_LAW_12462/

[29] Federal Law of 29.12.2012, No. 273-FZ "Education". Retrieved from: www.consultant.ru/ /document/cons doc LAW 140174/

[30] I. Dembovska, I. Silicka, V. Lubkina, Educational Tourism in the Training of Future Tourism Professionals // Society Integration Education. Proceedings of the International Scientific Conference 4 (2016) 245-255. 